\title{
Biomarkers for detection and surveillance of bladder cancer
}

\author{
Lorne I. Budman, MSc; Wassim Kassouf, MD; Jordan R. Steinberg, MD
}

\begin{abstract}
Introduction: Bladder cancer is the fourth most common cancer in men and the ninth most common cancer in women in Canada. Early detection of tumours is essential for improved prognosis and long-term survival. The standard method for detection and surveillance is cystoscopy together with urine cytology. Cystoscopy is relatively sensitive but is expensive and invasive. Urinary cytology is a noninvasive method that has poor sensitivity but high specificity; it is relied on for the detection of carcinoma in situ. Currently, several urinarybased bladder tumour biomarkers with USFDA/Health Canada approval are available commercially, but none have been widely adopted by urologists despite their offering high sensitivity and/or specificity. We present here a review of recent studies evaluating 7 commercial biomarker assays for the detection and/or surveillance of bladder cancer.
\end{abstract}

Results: Sensitivity and specificity ranges, respectively, for each marker were reported as follows: BTA Stat (Polymedco), 52.5\%-78.0\% and 69.0\%-87.1\%; BTA Trak (Polymedco), 51\%-100\% and 73\%-92.5\%; cytology, 12.1\%-84.6\% and $78.0 \%-100 \%$; hematuria dipstick, $47.0 \%-92.6 \%$ and $51.0 \%-84.0 \%$; NMP22 Bladder Cancer Test (Matritech), 34.6\%-100\% and 60.0\%-95.0\%; NMP22 BladderChek (Matritech), 49.5\%-65.0\% and $40.0 \%-89.8 \%$; ImmunoCyt/uCyt+ (DiagnoCure), $63.3 \%-84.9 \%$ and $62.0 \%-78.1 \%$; ImmunoCyt/uCyt+ and cytology, $81.0 \%-89.3 \%$ and $61.0 \%-77.7 \%$; and UroVysion (Abbott Molecular)/florescence in situ hybridization, 68.6\%-100\% and $65.0 \%-96.0 \%$.

Conclusion: We find that no currently available bladder cancer urinary marker is sensitive enough to eliminate the need for cystoscopy. In addition, cytology remains integral to the detection of occult cancer. However, owing to their relatively high sensitivities, these markers may be used to extend the period between cystoscopies in the surveillance of patients with transitional cell carcinoma. Further study is required to determine which markers, alone or in panel, would best accomplish this.

CUAJ 2008;2(3):212-21

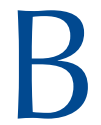

ladder cancer is the fourth most common cancer in men and the ninth most common cancer in women in Canada. ${ }^{1}$ The vast majority of patients with newly diagnosed bladder cancers have superficial, low-grade neoplasms that are associated with an excellent prognosis. However, these tumours have a $30 \%$ to $70 \%$ recurrence rate and may progress to invasive cancers in $10 \%$ to $30 \%$ of patients; progression greatly increases the risk of metastasis and subsequent mortality. ${ }^{2-4}$ For this reason, the early detection of bladder tumours is essential for improved patient prognosis and long-term survival.

Cytology and cystoscopy have been used as detection tests for patients suspicious for bladder cancer or for the surveillance of patients at risk of tumour recurrence. Cystoscopy is highly sensitive for most tumours but has some practical limitations. It may fail to identify smaller, flat tumours such as carcinoma in situ. Also, despite the technical advances in cystoscopes, the procedure is often perceived as invasive and a source of patient anxiety. ${ }^{5-7}$ There is also a significant financial cost related to frequent cystoscopic monitoring, in terms of health care resources and patient time. Conversely, urinary cytology is noninvasive and highly specific but has poor sensitivity for low-grade, well-differentiated lesions. Thus it cannot be used to replace (or prolong the intervals between) cystocopy and is used, rather, as an adjunct to help detect occult tumours.

Because cystoscopies are invasive and because cytology has poor sensitivity, noninvasive biomarkers have been sought as alternatives to cystoscopy and cytology for the detection and surveillance of bladder cancer. An ideal test for the detection of bladder tumours should be objective, accurate, rapid and easy to administer; moreover, it should offer high sensitivity and specificity. Whereas sensitivity is defined as the ability of a test to detect disease, specificity is defined as the ability to rule out disease. The positive and negative predictive values (PPV and NPV) are directly related to the sensitivity and specificity and the prevalence of the disease in the defined population (Box 1).

More than 20 known urine-based biomarkers with high sensitivity and/or specificity have been identified in the literature, and among these, 7 are available commercially with 
Health Canada approval for the detection and/or monitoring of bladder cancer. Although none of these tests have proven to be powerful enough to replace cystoscopy, they are all more sensitive than cytology. ${ }^{8-10}$ Their high sensitivity and high NPV suggest that they could be used as part of a surveillance regimen to increase the interval between cystoscopies. Despite this, urologists have been slow to adopt the use of these markers as an adjunct to existing surveillance and detection strategies. Reasons for this include the following: most of these markers are less specific than cytology, resulting in more false positives; some markers are unable to differentiate between urothelial malignancy and inflammation or other benign urologic conditions, again leading to false positives; large population studies have yet to be performed to evaluate these markers; and there are no standard protocols, cutoff values or scoring criteria for tests performed at different centres, meaning that studies by different groups cannot be readily compared. ${ }^{11}$ Still, we present here a brief review of recent studies for each of the urinary biomarker tests that are currently commercially available in Canada.

\section{Hematuria}

One of the most common signs of bladder cancer is gross or microscopic hematuria. Hematuria can be easily measured in the office or at home by using a hematuria dipstick assay, a low-cost test strip that can reproducibly measure the presence of blood in urine. It has been shown that $85 \%$ of bladder cancer patients have gross or microscopic hematuria. ${ }^{12,13}$ However, a wide range of benign inflammatory conditions not related to bladder cancer may also lead to detectable blood in the urine. Thus, although cancer without blood is rare, leading to high sensitivity, fewer than $5 \%$ of patients presenting with hematuria actually have bladder cancer, which translates to poor specificity and PPV. ${ }^{14,15}$ False-positive results may also have technical or biochemical origins, including test strips exposed to light and/or air, use of expired strips or the presence of oxidizing contaminants such as hypochlorite. The test strips are also sensitive to hemoglobin and myoglobin, and in the case of female patients, a false-positive test may result from lingering menstrual blood. ${ }^{16,17}$ Overall sensitivity values from recent studies using hematuria detection as a test for bladder cancer fall in the range of $47.0 \%-92.6 \%$, and reported specificity ranges from $51.0 \%-84.0 \%{ }^{12,18-22}$ (Table 1 ).

\section{Cytology}

Urinary cytology is the direct microscopic investigation of shed urothelial cells. The cells are typically harvested from a fresh-voided urine specimen. Cytology is noninvasive and offers nearly perfect specificity but lacks sensitivity, especially for low-grade tumours. It can be a challenging test to perform and is highly dependent on the skills and experience of a trained cytopathologist. Interobserver variation as well as sample preparation and stability result in a wide range of reported sensitivities across the studies presently under review $(12.1 \%-84.6 \%)^{12,19-41}$ (Table 1). Halling and colleagues $^{45}$ noted that for grade 1 , grade 2 and grade 3 bladder tumours, respectively, the gradeper-grade sensitivity of cytology before 1990 was $37 \%, 75 \%$ and $94 \%$ and that it decreased to $11 \%$, $31 \%$ and $60 \%$ after 1990 . The suspected reason for the drop in sensitivity is that, before 1990, studies were conducted by pathologists with great expertise in the field of urine cytology, whereas

\begin{tabular}{|c|c|}
\hline Characteristic & Definition \\
\hline Sensitivity & [True positve / (true positive + false negative)] $\times 100$ \\
\hline Specificity & [True negative / (true negative + false positive)] $\times 100$ \\
\hline $\begin{array}{l}\text { Positive predictive } \\
\text { value }\end{array}$ & [True Positve / (true positive + false positive)] $\times 100$ \\
\hline $\begin{array}{l}\text { Negative predictive } \\
\text { value }\end{array}$ & [True negative / (true negative + false negative) $] \times 100$ \\
\hline \multicolumn{2}{|c|}{$\begin{array}{l}\text { False negative = no. of patients with disease who scored a negative marker test; false positive }=\text { no. of patients without disease } \\
\text { who scored a positive marker test; true negative }=\text { no. of patients without disease who scored a negative marker test; true } \\
\text { positive }=\text { no. of patients with disease who scored a positive marker test. } \\
\text { Note: Patients with disease had a positive cystoscopy; patients without disease had a negative cystoscopy. }\end{array}$} \\
\hline
\end{tabular}


more recently, cytology has become one of many tests performed by general pathologists lacking direct expertise in urine cytology ${ }^{45}$ Still, cytol- ogy remains the gold standard for the detection of occult carcinoma in situ, which largely accounts for its continued widespread use. ${ }^{31,46}$

\begin{tabular}{|c|c|c|c|c|}
\hline $\begin{array}{l}\text { Type of marker and } \\
\text { study }\end{array}$ & $\begin{array}{l}\text { Total no. of tests } \\
\text { with positive } \\
\text { cystoscopy }\end{array}$ & $\begin{array}{c}\text { Sensitivity, } \\
\%\end{array}$ & $\begin{array}{l}\text { Total no. of tests } \\
\text { with negative } \\
\text { cystoscopy }\end{array}$ & $\begin{array}{l}\text { Specificity, } \\
\%\end{array}$ \\
\hline \multicolumn{5}{|l|}{ Cytology } \\
\hline Abd El Gawad et al. ${ }^{23}$ & 46 & 54.3 & 40 & 100.0 \\
\hline Babjuk et al. ${ }^{24}$ & 78 & 33.3 & 140 & 100.0 \\
\hline Bhuiyan et al. ${ }^{20}$ & 67 & 40.0 & 58 & 95.0 \\
\hline Boman et al. ${ }^{22}$ & 87 & 42.0 & 61 & 97.0 \\
\hline Grossman et al. ${ }^{25}$ & 76 & 15.8 & 1211 & 99.2 \\
\hline Grossman et al. ${ }^{26}$ & 98 & 12.2 & 552 & 96.9 \\
\hline Hautmann et al. ${ }^{27}$ & 30 & 73.0 & 64 & 79.7 \\
\hline Krause et al. ${ }^{28}$ & 69 & 70.0 & 33 & 85.0 \\
\hline Kumar et al. ${ }^{29}$ & 46 & 41.3 & 85 & 96.4 \\
\hline Laudadio et al. ${ }^{30}$ & 44 & 34.0 & 55 & 93.0 \\
\hline Lodde et al. ${ }^{31}$ & 101 & 48.5 & 176 & 94.9 \\
\hline Messing et al. ${ }^{32}$ & 52 & 23.0 & 274 & 93.0 \\
\hline Mian et al. ${ }^{33}$ & 298 & 38.9 & 1588 & 99.4 \\
\hline Moonen et al. ${ }^{34}$ & 29 & 42.9 & 77 & 93.2 \\
\hline Parekattil et al..$^{19}$ & 27 & 66.7 & 226 & 81.0 \\
\hline Saad et al. ${ }^{21}$ & 52 & 48.0 & 68 & 87.0 \\
\hline Sarosdy et al. ${ }^{35}$ & 51 & 38.0 & N/A & N/A \\
\hline Schroeder et al. ${ }^{12}$ & 34 & 70.6 & 58 & 81.0 \\
\hline Shariat et al..$^{36}$ & 898 & 70.0 & N/A & $\mathrm{N} / \mathrm{A}$ \\
\hline Sun $Y$ et al. ${ }^{37}$ & 151 & 36.4 & 100 & 100.0 \\
\hline Tetu et al. ${ }^{38}$ & 136 & 29.0 & 734 & 98.0 \\
\hline Toma et al. ${ }^{39}$ & 42 & 84.6 & 84 & 80.0 \\
\hline Tritschler et al. ${ }^{40}$ & 40 & 44.0 & 60 & 78.0 \\
\hline Tsui et al. ${ }^{41}$ & 135 & 23.5 & 50 & 96.9 \\
\hline \multicolumn{5}{|l|}{ Hematuria Dipstick } \\
\hline Bhuiyan et al. ${ }^{20}$ & 70 & 47.0 & 163 & 82.0 \\
\hline Boman et al. ${ }^{22}$ & 87 & 47.0 & 38 & 84.0 \\
\hline Halling et al. ${ }^{18}$ & 73 & 74.0 & 80 & 51.0 \\
\hline Parekattil et al..$^{19}$ & 27 & 92.6 & 226 & 51.8 \\
\hline Saad et al. ${ }^{21}$ & 52 & 50.0 & 68 & 54.0 \\
\hline Schroeder et al. ${ }^{12}$ & 59 & 50.8 & 78 & 78.2 \\
\hline \multicolumn{5}{|l|}{ BTA Stat } \\
\hline Babjuk et al. ${ }^{24}$ & 78 & 74.4 & 140 & 87.1 \\
\hline Bhuiyan et al. ${ }^{20}$ & 70 & 76.0 & 163 & 69.0 \\
\hline Boman et al. ${ }^{22}$ & 88 & 78.0 & 61 & 73.0 \\
\hline Halling et al. ${ }^{18}$ & 72 & 78.0 & 80 & 74.0 \\
\hline Saad et al. ${ }^{21}$ & 52 & 63.0 & 68 & 82.0 \\
\hline Schroeder et al. ${ }^{12}$ & 59 & 52.5 & 77 & 76.7 \\
\hline Sun $Y$ et al. ${ }^{37}$ & 151 & 76.8 & 100 & 87.0 \\
\hline \multirow[t]{2}{*}{ Toma et al. ${ }^{39}$} & 42 & 66.6 & 84 & 78.2 \\
\hline & \multicolumn{4}{|c|}{ Continued on next page } \\
\hline
\end{tabular}




\section{Bladder tumour antigen test}

The bladder tumour antigen test (BTA) is a test based on antibodies that detects elevated levels of the complement factor $\mathrm{H}$-related protein (CFHrp) in voided urine (product insert). This protein is similar in structure and function to human complement factor $\mathrm{H}(\mathrm{FH})$ and is released by normal cells

Table 1. continued

\begin{tabular}{|c|c|c|c|c|}
\hline $\begin{array}{l}\text { Type of marker and } \\
\text { study }\end{array}$ & $\begin{array}{l}\text { Total no. of tests } \\
\text { with positive } \\
\text { cystoscopy }\end{array}$ & $\begin{array}{c}\text { Sensitivity, } \\
\%\end{array}$ & $\begin{array}{l}\text { Total no. of tests } \\
\text { with negative } \\
\text { cystoscopy }\end{array}$ & $\begin{array}{l}\text { Specificity, } \\
\%\end{array}$ \\
\hline \multicolumn{5}{|l|}{ BTA Trak } \\
\hline Abd El Gawad et al..$^{23}$ & 46 & 100.0 & 40 & 92.5 \\
\hline Babjuk et al. ${ }^{24}$ & 78 & 75.6 & 140 & 72.6 \\
\hline Tsui et al. ${ }^{41}$ & 135 & 51.0 & 50 & 73.0 \\
\hline \multicolumn{5}{|l|}{ ImmunoCyt / uCyt+ } \\
\hline Hautmann et al. ${ }^{27}$ & 30 & $63.3 / 83.3$ & 64 & $75.0 / 85.9$ \\
\hline Lodde et al. ${ }^{31}$ & 101 & 84.2 / 86.1 & 176 & $78.1 / 77.7$ \\
\hline Messing et al. ${ }^{32}$ & 52 & $81.0 / 81.0$ & 274 & $75.0 / 73.0$ \\
\hline Mian et al. ${ }^{33}$ & 298 & $84.9 / 89.3$ & 1588 & $72.5 / 72.5$ \\
\hline Têtu et al. ${ }^{38}$ & 100 & $74.0 / 84.0$ & 453 & $62.0 / 61.0$ \\
\hline Toma et al. ${ }^{39}$ & 42 & $78.3 / 89.1$ & 84 & $73.8 / 72.5$ \\
\hline \multicolumn{5}{|l|}{$\begin{array}{l}\text { NMP22 Bladder } \\
\text { Cancer Test }\end{array}$} \\
\hline Abd El Gawad et al..$^{23}$ & 46 & 91.3 & 40 & 87.5 \\
\hline Bhuiyan et al. ${ }^{20}$ & 67 & 61.0 & 162 & 60.0 \\
\hline Boman et al. ${ }^{22}$ & 89 & 75.0 & 60 & 73.0 \\
\hline Chang et al. ${ }^{42}$ & 28 & 50.0 & 303 & 82.8 \\
\hline Parekattil et al. ${ }^{19}$ & 27 & 70.4 & 225 & 45.6 \\
\hline Saad et al. ${ }^{21}$ & 52 & 81.0 & 68 & 87.0 \\
\hline Shariat et al. ${ }^{36}$ & 898 & 73.3 & N/A & N/A \\
\hline Shariat et al. ${ }^{11}$ & 1045 & 73.5 & 1826 & 81.0 \\
\hline Sun $Y$ et al. ${ }^{37}$ & 151 & 77.5 & 100 & 81.0 \\
\hline Toma et al. ${ }^{39}$ & 42 & 68.5 & 84 & 65.2 \\
\hline Tsui et al. ${ }^{41}$ & 135 & 77.5 & 50 & 73.5 \\
\hline \multicolumn{5}{|l|}{$\begin{array}{l}\text { NMP22 } \\
\text { BladderChek }\end{array}$} \\
\hline Grossman et al..$^{25}$ & 76 & 55.7 & 1252 & 85.7 \\
\hline Grossman et al. ${ }^{26}$ & 98 & 49.5 & 565 & 87.3 \\
\hline Kumar et al. ${ }^{29}$ & 46 & 84.8 & 85 & 77.6 \\
\hline Moonen et al. ${ }^{34}$ & 29 & 57.1 & 77 & 89.8 \\
\hline Tritschler et al. ${ }^{40}$ & 40 & 65.0 & 60 & 40.0 \\
\hline \multicolumn{5}{|l|}{$\begin{array}{l}\text { UroVysion/ } \\
\text { florescence in situ } \\
\text { hybridization }\end{array}$} \\
\hline Bollmann et al. ${ }^{43}$ & 13 & 100.0 & 34 & N/A \\
\hline Constantinou et al. ${ }^{44}$ & 25 & 96.0 & N/A & N/A \\
\hline Halling et al. ${ }^{18}$ & 73 & 81.0 & 80 & 96.0 \\
\hline Krause et al. ${ }^{28}$ & 69 & 83.0 & 33 & 71.0 \\
\hline Laudadio et al. ${ }^{30}$ & 44 & 73.0 & 55 & 65.0 \\
\hline Sarosdy et al. ${ }^{35}$ & 51 & 68.6 & 422 & 77.7 \\
\hline Toma et al. ${ }^{39}$ & 42 & 68.8 & 84 & 89.1 \\
\hline
\end{tabular}


to protect them from being targeted by the body's own immune system. CFHrp has been shown to be released by tumour cells in culture, and may play an in vivo role in helping tumour cells to evade attack by the host's immune defenses. ${ }^{47}$ There are 2 BTA-based tests currently available, the qualitative, point-of-care BTA Stat (Polymedco) and BTA Trak (Polymedco), which is an enzymelinked immunosorbent type of qualitative assay. Reported sensitivity ranges for these tests are $52.5 \%-78.0 \%$ for BTA Stat and $51.0 \%-100 \%$ for BTA Trak (Table 1). BTA Stat specificity has been reported in the range of $69.0 \%-87.1 \%$, and the range for BTA Trak is $73.0 \%-92.5 \%$. $^{12,18,20-24,37,39}$ Both tests are more sensitive but less specific than cytology, owing to the fact that they are affected by benign inflammatory conditions, calculi, foreign bodies, recent instrumentation, bowel interposition segment or another genitourinary cancer, which can lead to false-positive results. ${ }^{48}$ Past bacille Calmette-Guérin (BCG) therapy, recent intravesical instillation and factors including nicotine, caffeine, acetylsalicylic acid and acetaminophen may also result in false-positive BTA scores. ${ }^{49,50}$ Both BTA tests are approved for the surveillance of recurrent bladder cancer.

\section{Nuclear matrix protein 22}

Nuclear matrix proteins (NMPs) are part of the structural framework of the nucleus and provide support for the nuclear shape. ${ }^{51}$ These proteins have also been attributed roles in DNA replication, in ribonucleic acid transcription and in the regulation of gene expression..$^{52,53}$ One member of this family, nuclear mitotic apparatus protein (NMP22), is much more prevalent in malignant urothelial cells than in their normal counterparts. Apoptosis is accompanied with a release of NMP22 into the urine, and patients with bladder cancer have a significantly elevated concentration of NMP22, reported to be as high as 25 times that of normal concentrations. ${ }^{51,54}$ There are 2 marker tests for bladder cancer that rely on detecting NMP22 in voided urine: the original NMP22 Bladder Cancer Test (Matritech), which is a quantitative, sandwichtype immunoassay, and the NMP22 BladderChek (Matritech), which is a qualitative point-of-care test cartridge containing the NMP22 detecting and reporter antibodies.

Reported sensitivity ranges are $34.6 \%-100 \%$, and $49.5 \%-65.0 \%$, for the Bladder Cancer Test and BladderChek assays, respectively (Table 1 ). Specificity of the Bladder Cancer Test is reported to be $60.0 \%-95.0 \%$, and specificity of the NMP22 BladderChek is reportedly in the range of 40.0\%-89.8\%. . $11,19-23,25,26,32,34,36,37,39-42$ The NMP22 tests are based on the release of NMPs into the urine following apoptosis of the urothelial cells, a process that can also occur as a result of benign conditions. As is the case with the BTA tests, NMP22 levels are raised in patients with urinary tract infections, concurrent urolithiasis, history of bladder interposition, other malignancies, intravesical therapies and even cystoscopy, all of which may contribute to false-positive results. ${ }^{11,42}$ Some studies have excluded patients with these confounding factors, which improves the specificity and PPV and contributes to the large variation of reported performance characteristics.

Another consideration relates to the selected cut-off value for test positivity, which varies widely across reported studies for the quantitative assays for both NMP22 and BTA. Although the manufacturer recommends a cut-off of $10 \mathrm{U} / \mathrm{mL}$ for the NMP22 Bladder Cancer Test, cut-offs ranging from 3.6 to $27 \mathrm{U} / \mathrm{mL}$ have been reported. A high cutoff will lead to fewer false-positive scores at a cost of lower sensitivity. Conversely, sensitivity can be improved by lowering the cut-off, but specificity will be reduced. Some researchers suggest that the test cut-off should be selected according to the needs of the patient population being tested. ${ }^{11}$ Although flexibility in the cut-off may allow tailored use of these tests, it makes comparison between studies more difficult. Cut-off variability is not an issue for the point-of-care NMP22 BladderChek and BTA Stat tests, where a fixed cutoff is universally applied. However, Shariat and colleagues ${ }^{11}$ suggest that the reduction of all cancerrelated factors to a single, arbitrary cut-off value could lead to "spectrum bias." Spectrum bias refers to the fact that, for an arbitrary cut-off such as $10 \mathrm{U} / \mathrm{mL}$, a score of $9.9 \mathrm{U} / \mathrm{mL}$ would be classified as a negative test result when such a level may in fact be clinically relevant and indicative of disease. To emphasize this point, an example considered only patients with measured NMP22 levels between 9 and $11 \mathrm{U} / \mathrm{mL}$, with $10 \mathrm{U} / \mathrm{mL}$ as cut-off; of 83 patients scoring below $10 \mathrm{U} / \mathrm{mL}$, $19(23 \%)$ had cancer, whereas of 71 patients scoring above $10 \mathrm{U} / \mathrm{mL}, 37$ (52\%) did not have 
cancer. ${ }^{11}$ The fixed cut-off values of the point-ofcare tests may lead to easier comparison through universality, but these tests are affected to a greater extent by spectrum bias than their quantitative counterparts. The NMP22 tests have been approved for both the detection of new cancers and the surveillance of recurrent tumours, and the NMP22 BladderChek is the only point-of-care test to receive this distinction.

\section{ImmunoCyt/uCyt+}

Whereas the hematuria dipstick, BTA and NMP22 assays detect molecules present in urine, other assays are based on changes occurring at the cellular level. The ImmunoCyt/uCyt+ test (Diagnocure) is an immunocytological fluorescence assay designed to improve the sensitivity of cytology. A cocktail of 3 monoclonal antibodies is used to detect antigens originating specifically from tumours of transitional epithelial cells. The M344 and LDQ10 antibodies are labelled with fluorescein, a green fluorescence, and will recognize a mucin-like antigen located in the urine on exfoliated tumour cells. The 19A211 antibody will recognize the presence of a high molecular weight glycosylated form of carcinoembrionic antigen and is labelled with Texas Red. ${ }^{55}$ Cells collected from urine are fixed to a slide and analyzed by a pathologist using a fluorescent microscope equipped with appropriate filters. A test is scored as positive when a single red or green cell is observed, although the manufacturer recommends all positive cells be correlated to morphology. A slide must contain a minimum of 500 cells for a negative score to be valid. ${ }^{56}$

Unlike other urinary markers, ImmunoCyt/uCyt+ is not approved as a stand-alone test but, rather, is only approved for use as a surveillance test in conjunction with cytology, which makes direct comparison with other markers difficult. ${ }^{26}$ Overall sensitivity of the combined ImmunoCyt/uCyt+ and cytology assay is reportedly in the range of $81.0 \%-89.3 \%$, which is an improvement over either test on its own (Table 1). Specificity of the combined assay reaches $61.0 \%-77.7 \%$, which is less than that offered by cytology alone..$^{27,31-33,38,39}$ The ImmunoCyt/uCyt+ assay requires technical expertise, extensive sample handling and preparation and specialized equipment. However, a person with minimal cytology training and experience can perform the test. In fact, smaller laboratories with the necessary equipment have reported results equivalent to those of larger, dedicated laboratory facilities..$^{31}$ In general, studies suggest that ImmunoCyt/uCyt+ has superior sensitivity over cytology for pathological stage Ta-T2 and grade 1-2 tumours and similar or better sensitivity for grade 3 tumours and carcinoma in situ. ${ }^{31,32,38}$ Unlike the molecular-based tests, ImmunoCyt/uCyt+ is relatively unaffected by benign conditions and instillation therapy. ${ }^{57}$ Still, this test, like cytology, remains subjective and depends in part on the technician. Observer experience, specimen stability and handling and differences in sample size may explain the variation in reported ImmunoCyt/uCyt+ sensitivity. ${ }^{27}$

\section{UroVysion}

Another fluorescence-based cellular assay is the UroVysion assay (Abbott Molecular), which uses fluorescence in situ hybridization (FISH) to visually inspect chromosome copy numbers and specific DNA sequences directly in the cell nucleus. ${ }^{28,58}$ Genetic alterations resulting in bladder cancer are most frequently found in chromosomes $1,3,5,7,9,11$ and $17 .{ }^{28,59-61}$ The UroVysion assay uses a multitarget set of probes that hybridize to the centromeres of chromosomes 3, 7 and 17 and to the 9p21 locus of chromosome 9. The loss of the 9p21 locus, site of the p16 tumour suppressor gene, is the earliest and most frequent genetic aberration in bladder cancer. ${ }^{62}$

Recent published series on the FISH assay have demonstrated results in the range of $68.6 \%-100 \%$ and $65.0 \%-96.0 \%$ for sensitivity and specificity, respectively $18,28,30,35,39,43,44,58,62,63$ (Table 1 ). Thus the UroVysion assay, which has received FDA approval for the detection of recurrent bladder cancer, is more sensitive than urinary cytology but provides a similar, or slightly lower, specificity. In all studies, sensitivity increased with higher cancer grade. The FISH method examines changes at the nuclear level of the cell and is therefore unaffected by any benign conditions of the patient; it has been approved for use in patients with hematuria. ${ }^{30,35}$ Kipp and colleagues ${ }^{64}$ demonstrated that the UroVysion assay might be used to monitor the effects of BCG and other intravesicle therapies where a positive FISH assay results in a high likelihood for the progression to muscle-invasive disease. ${ }^{64}$ Variation in scoring criteria, the use of 
voided urine as opposed to bladder-wash urine, observer experience and sample stability and handling contribute to the variation of reported performance. Criticism of this method typically focuses on the high cost of the probes and the need for expensive equipment (fluorescent microscopes, specific filters, etc.) and trained technical personnel..$^{28}$ The test is not point-of-care, and is timeconsuming and not suited to high-throughput screening.

There is an important consideration with regard to false-positive results with the FISH test. Several studies have reported the detection of recurrent tumours within weeks or months after a falsepositive test result. Although it is always possible that these tumours were originally overlooked during the original cystoscopy, others suggest that the assays are sensitive enough to detect changes occurring at the cellular level before the development of endoscopically visible lesions. Halling and colleagues ${ }^{18}$ have termed the latter phenomenon the "anticipatory positive" result; these authors reported recurrences in 7 of 13 patients within 3-12 months after a false-positive FISH score. Studies with other marker tests have also addressed the predictive value of false-positive results ${ }^{29,40,65}$ and include a study by Pode and colleagues, ${ }^{66}$ who discussed false-positive results with the BTA Stat test. However, Friedrich and colleagues $^{67}$ have argued that false-positive BTA Stat tests can be expected, owing to the influence of many benign conditions, and that cystoscopy will often fail to detect small lesions and carcinoma in situ. Whereas other reports focused strictly on falsepositive results, Friedrich and colleagues compared recurrences after false-positive and true-negative scores and determined that there was no significant difference among these groups with use of the BTA Stat, NMP22 Bladder Cancer Test or ImmunoCyt/uCyt+. ${ }^{67}$ Nevertheless, it remains advisable to closely monitor patients in the weeks and months after a false-positive test result. ${ }^{30}$

The current surveillance protocol for bladder cancer patients calls for cystoscopy with cytology every 3 months for the first 1-2 years, then every 6 months for $1-5$ years and then yearly afterwards, provided no recurrent tumours are detected. This is a very costly endeavour and does not take into consideration the fact that not all patients are at equal risk for tumour recurrence. ${ }^{31}$ Although not powerful enough to replace cystoscopy, urinary biomarkers may be useful in extending the time between cystoscopic examinations because of their relatively high sensitivity and high NPV (especially for higher-grade lesions). In a recent study evaluating the ImmunoCyt/uCyt+ test, Lodde and colleagues ${ }^{31}$ ranked patients as low-, intermediate- or high-risk for tumour recurrence according to tumour size and initial stage and grade of the malignancy. Although 30 of 84 low-risk patients developed recurrent tumours within 3-96 months, all lesions were stage pTaG1, and there were no cases of progression into the muscle. These authors concluded that after resection and an initial cystoscopy at 3 months, a follow-up protocol of yearly cystoscopy and testing with ImmunoCyt/uCyt+ and cytology every 6 months could result in a significant cost savings without placing the patient at a greater risk for disease progression. ${ }^{31}$

Other recent studies have considered the economic impact of the use of urinary biomarkers, particularly in the screening of patients for bladder cancer. Such considerations are directly dependent on the incidence of the disease as well as on the sensitivity and specificity of the marker, in addition to the overall costs of each test.' Lotan and colleagues ${ }^{6}$ reported that screening of all men aged 55 years or older was significantly more costly on a per-cancer basis than screening only in a highrisk group (more than US\$400 000 v. \$3130). Svatek and colleagues ${ }^{7}$ suggest that marker screening of a high-risk group could be cost effective, although additional studies in an asymptomatic cohort are required before screening of a general population is recommended.

Although no ideal marker currently exists, a distinction should be made between the usefulness of a marker for the detection of de novo bladder tumours as compared with the monitoring of recurrent tumours in bladder cancer patients. For the detection of new tumours (e.g., in a screening population), a marker must have a high sensitivity for all tumours, even at the expense of a lower specificity. In the surveillance or monitoring setting, delayed diagnosis of a low-grade recurrent lesion will be unlikely to affect the patient's prognosis, and as such, the sensitivity for high-grade lesions would be more important. A test with a high sensitivity for high-grade tumours would result in a high NPV (for high-grade tumours), and this would be useful in prolonging the time interval between cystoscopies. 


\section{Future directions}

In addition to the currently available markers, the search for more sensitive and specific biomarkers of cancer is ongoing. Promising results have been reported for markers that include telomerase, survivin, aurora-A and others, all of which remain at the experimental stage. While one or more of these may yet prove to be an improvement over the currently available markers, many believe that no single marker will be powerful enough to replace cystoscopy. Instead, the desired prognostic or diagnostic test may involve the use of several less sensitive and specific markers combined together in a panel..$^{68,69}$

The creation of these biomarker panels has entered the realm of possibility as a result of the completion of the Human Genome Project, advances in high-throughput technology and the development and integration of computational biology. ${ }^{69}$ Although it was initially believed that microarray technology would help identify overexpressed genes as biomarkers, it now seems apparent that a better approach is through analysis at the level of the proteome. ${ }^{68}$ Several proteomics-based methods have been described for biomarker discovery, including 2-dimensional polyacrylamide gel electrophoresis (2D-PAGE) and various mass spectrometry (MS) techniques. Several studies used 2D-PAGE to discover 4 proteins, A-FABP, GST- $\mu$, PGDH and keratin 13, which are expressed in normal urothelium and low-grade transitional cell carcinoma (TCC), but not in high-grade TCC. ${ }^{70-72}$ Surface-enhanced laser desorption ionization time-of-flight (SELDI-TOF) MS is a low-resolution technique that can provide reproducible protein profiles generated from crude biological fluids such as serum and urine. ${ }^{73}$ Despite some recent criticism regarding certain technological aspects, the SELDI-TOF method has been applied toward biomarker discovery in prostate, ovarian, breast and other cancers. ${ }^{68,74}$ Using SELDITOF MS to analyze urine protein profiles from patients with TCC, Vlahou and colleagues ${ }^{75}$ discovered a combination of protein biomarkers and clusters with $77 \%$ sensitivity and $66 \%$ specificity for bladder cancer. More recently, advances in liquid chromatography-tandem MS technologies, which permit direct peptide sequencing, are beginning to emerge as the premiere method for biomarker identification and validation.
In conclusion, none of the currently available bladder cancer urinary markers are sensitive enough to eliminate the need for cystoscopy. In addition, cytology remains integral in the detection of occult cancer. However, owing to their relatively high sensitivities, these markers may be used to extend the period between cystoscopies in the surveillance of patients with TCC. Further study is required to determine which markers, alone, or in panel, would best accomplish this.

From the Division of Urology, McGill University Health Centre, Montréal, Que.

This article has been peer reviewed.

Competing interests: None declared.

\section{References}

1. Canadian Cancer Society. Canadian cancer statistics 2006. Available: www.cancer.ca/vgn/images/portal/cit_86751114/31/21/935505792cw_2006s tats_en.pdf.pdf (accessed 2008 Apr 10).

2. Rubben $\mathrm{H}$, Lutzeyer $\mathrm{W}$, Fischer $\mathrm{N}$, et al. Natural history and treatment of low and high risk superficial bladder tumors. J Urol 1988;139:283-5.

3. Heney NM, Ahmed S, Flanagan MJ, et al. Superficial bladder cancer: progression and recurrence. J Urol 1983;130:1083-6.

4. Millan-Rodriguez F, Chechile-Toniolo G, Salvador-Bayari J, et al. Primary superficial bladder cancer risk groups according to progression, mortality and recurrence. J Urol 2000;164:680-4.

5. Avritscher EB, Cooksley CD, Grossman HB, et al. Clinical model of lifetime cost of treating bladder cancer and associated complications. Urology 2006;68:549-53.

6. Lotan Y, Svatek RS, Sagalowsky Al. Should we screen for bladder cancer in a highrisk population? A cost per life-year saved analysis. Cancer 2006;107:982-90.

7. Svatek RS, Sagalowsky Al, Lotan Y. Economic impact of screening for bladder cancer using bladder tumor markers: a decision analysis. Urol Oncol 2006;24:338-43.

8. Lotan Y, Roehrborn CG. Sensitivity and specificity of commonly available bladder tumor markers versus cytology: results of a comprehensive literature review and meta-analyses. Urology 2003;61:109-18; discussion 118.

9. van Rhijn BW, van der Poel HG, van der Kwast TH. Urine markers for bladder cancer surveillance: a systematic review. Eur Urol 2005;47:736-48.

10. Dey P. Urinary markers of bladder carcinoma. Clin Chim Acta 2004;340:57-65.

11. Shariat SF, Marberger MJ, Lotan Y, et al. Variability in the performance of nuclear matrix protein 22 for the detection of bladder cancer. J Urol 2006; 176:919-26; discussion 926.

12. Schroeder GL, Lorenzo-Gomez MF, Hautmann SH, et al. A side by side comparison of cytology and biomarkers for bladder cancer detection. J Urol 2004;172:1123-6.

13. Friedman GD, Carroll PR, Cattolica EV, et al. Can hematuria be a predictor as well as a symptom or sign of bladder cancer? Cancer Epidemiol Biomarkers Prev 1996;5:993-6.

14. Messing EM, Vaillancourt A. Hematuria screening for bladder cancer. J Occup Med 1990;32:838-45.

15. Britton JP, Dowell AC, Whelan $P$, et al. A community study of bladder cancer screening by the detection of occult urinary bleeding. J Urol 1992;148:788-90.

16. Khan MA, Shaw G, Paris AM. Is microscopic haematuria a urological emergency? BJU Int 2002;90:355-7.

17. Hemastix [package insert]. Leverkusen (DE): Bayer; 2007.

18. Halling KC, King W, Sokolova IA, et al. A comparison of BTA stat, hemoglobin dipstick, telomerase and Vysis UroVysion assays for the detection of urothelial carcinoma in urine. J Urol 2002;167:2001-6.

19. Parekattil SJ, Fisher HA, Kogan BA. Neural network using combined urine nuclear matrix 
protein-22, monocyte chemoattractant protein-1 and urinary intercellular adhesion molecule-1 to detect bladder cancer. J Urol 2003;169:917-20.

20. Bhuiyan J, Akhter J, O'Kane DJ. Performance characteristics of multiple urinary tumor markers and sample collection techniques in the detection of transitional cell carcinoma of the bladder. Clin Chim Acta 2003;331:69-77.

21. Saad A, Hanbury DC, McNicholas TA, et al. A study comparing various noninvasive methods of detecting bladder cancer in urine. BJU Int 2002;89:369-73.

22. Boman $\mathrm{H}$, Hedelin $\mathrm{H}$, Jacobsson S, et al. Newly diagnosed bladder cancer: the relationship of initial symptoms, degree of microhematuria and tumor marker status. J Urol 2002; 168:1955-9.

23. Abd El Gawad IA, Moussa HS, Nasr MI, et al. Comparative study of NMP-22, telomerase, and BTA in the detection of bladder cancer. J Egypt Natl Canc Inst 2005;17: 193-202.

24. Babjuk M, Kostirova M, Mudra K, et al. Qualitative and quantitative detection of urinary human complement factor H-related protein (BTA stat and BTA TRAK) and fragments of cytokeratins 8, 18 (UBC rapid and UBC IRMA) as markers for transitional cell carcinoma of the bladder. Eur Urol 2002;41:34-9.

25. Grossman HB, Messing E, Soloway $M$, et al. Detection of bladder cancer using a point-of-care proteomic assay. JAMA 2005;293:810-6.

26. Grossman HB, Soloway M, Messing E, et al. Surveillance for recurrent bladder cancer using a point-of-care proteomic assay. JAMA 2006;295:299-305.

27. Hautmann S, Toma M, Lorenzo Gomez MF, et al. Immunocyt and the HA-HAase urine tests for the detection of bladder cancer: a side-by-side comparison. Eur Urol 2004;46:466-71.

28. Krause FS, Rauch A, Schrott KM, et al. Clinical decisions for treatment of different staged bladder cancer based on multitarget fluorescence in situ hybridization assays? World J Urol 2006;24:418-22.

29. Kumar A, Kumar R, Gupta NP. Comparison of NMP22 BladderChek test and urine cytology for the detection of recurrent bladder cancer. Jpn I Clin Oncol 2006;36:172-5.

30. Laudadio J, Keane TE, Reeves HM, et al. Fluorescence in situ hybridization for detecting transitional cell carcinoma: implications for clinical practice. BJU Int 2005;96:1280-5.

31. Lodde M, Mian C, Comploj E, et al. uCyt+ test: alternative to cystoscopy for less-invasive follow-up of patients with low risk of urothelial carcinoma. Urology 2006;67:950-4.

32. Messing EM, Teot L, Korman H, et al. Performance of urine test in patients monitored for recurrence of bladder cancer: a multicenter study in the United States. J Urol 2005; 174:1238-41.

33. Mian C, Maier K, Comploj E, et al. uCyt+/ImmunoCyt in the detection of recurrent urothelial carcinoma: an update on 1991 analyses. Cancer 2006;108:60-5.

34. Moonen PM, Kiemeney LA, Wities JA. Urinary NMP22 BladderChek test in the diagnosis of superficial bladder cancer. Eur Urol 2005;48:951-6; discussion 956.

35. Sarosdy MF, Kahn PR, Ziffer MD, et al. Use of a multitarget fluorescence in situ hybridization assay to diagnose bladder cancer in patients with hematuria. J Urol 2006;176: 44-7.

36. Shariat SF, Zippe C, Ludecke G, et al. Nomograms including nuclear matrix protein 22 for prediction of disease recurrence and progression in patients with $\mathrm{Ta}$, $\mathrm{Tl}$ or CIS transitional cell carcinoma of the bladder. J Urol 2005; 173:1518-25.

37. Sun Y, He DL, Ma Q, et al. Comparison of seven screening methods in the diagnosis of bladder cancer. Chin Med J (Engl) 2006;119:1763-71.

38. Tetu B, Tiquert R, Harel F, et al. ImmunoCyt/uCyt+ improves the sensitivity of urine cytology in patients followed for urothelial carcinoma. Mod Pathol 2005; 18:83-9.

39. Toma MI, Friedrich MG, Hautmann SH, et al. Comparison of the ImmunoCyt test and urinary cytology with other urine tests in the detection and surveillance of bladder cancer. World J Urol 2004;22:145-9

40. Tritschler S, Scharf S, Karl A, et al. Validation of the diagnostic value of NMP22 BladderChek Test as a marker for bladder cancer by photodynamic diagnosis. Eur Urol 2007;51:403-8.

41. Tsui KH, Chen SM, Wang TM, et al. Comparisons of voided urine cytology, nuclear matrix protein-22 and bladder tumor associated antigen tests for bladder cancer of geriatric male patients in Taiwan, China. Asian J Androl 2007;9:711-5.

42. Chang $Y H, W_{U} C H$, Lee YL, et al. Evaluation of nuclear matrix protein-22 as a clinical diagnostic marker for bladder cancer. Urology 2004;64:687-92.
43. Bollmann M, Heller H, Bankfalvi A, et al. Quantitative molecular urinary cytology by fluorescence in situ hybridization: A tool for tailoring surveillance of patients with superficial bladder cancer? BJU Int 2005;95:1219-25.

44. Constantinou M, Binka-Kowalska A, Borkowska E, et al. Application of multiplex FISH, CGH and MSSCP techniques for cytogenetic and molecular analysis of transitional cell carcinoma (TCC) cells in voided urine specimens. J Appl Genet 2006;47:273-5.

45. Halling KC, King W, Sokolva IA, et al. A comparison of cytology and fluorescence in situ hybridization for the detection of urothelial carcinoma. J Urol 2000;164:1768-75.

46. Bastacky S, Ibrahim S, Wilcyznski SP, et al. The accuracy of urinary cytology in daily practice. Cancer 1999:87:118-28.

47. Kinders $R$, Jones $T$, Root $R$, et al. Complement factor $H$ or a related protein is a marker for transitional cell cancer of the bladder. Clin Cancer Res 1998;4:2511-20.

48. Sharma $S$, Zippe CD, Pandrangi L, et al. Exclusion criteria enhance the specificity and positive predictive value of NMP22 and BTA stat. J Urol 1999;162:53-7.

49. Raitanen MP, Hellstrom P, Marrilla $T$, et al. Effect of intravesical instillations on the human complement factor $\mathrm{H}$ related protein (BTA stat) test. Eur Urol 2001;40:422-6.

50. Liou LS. Urothelial cancer biomarkers for detection and surveillance. Urology 2006;67(Suppl 1):25-33; discussion 33-4.

51. Berezney R, Coffey DS. Identification of a nuclear protein matrix. Biochem Biophys Res Commun 1974;60:1410-7

52. Pardoll DM, Vogelstein B, Coffey DS. A fixed site of DNA replication in eucaryotic cells. Cell 1980; 19:527-36.

53. Gordon JN, Shu WP, Schlussel RN, et al. Altered extracellular matrices influence cellular processes and nuclear matrix organizations of overlying human bladder urothelial cells. Cancer Res 1993;53:4971-7.

54. Fey EG, Krochmalnic G, Penman $S$. The nonchromatin substructures of the nucleus: the ribonucleoprotein (RNP)-containing and RNP-depleted matrices analyzed by sequential fractionation and resinless section electron microscopy. J Cell Biol 1986;102:1654-65.

55. Fradet $Y$, Lockhard C. Performance characteristics of a new monoclonal antibody test for bladder cancer: ImmunoCyt trade mark. Can J Urol 1997;4:400-5.

56. ImmunoCyt/uCyt+ [package insert]. Québec: DiagnoCure; 2006.

57. Mian C, Lodde M, Comloj E, et al. The value of the ImmunoCyt/uCyt+ test in the detection and follow-up of carcinoma in situ of the urinary bladder. Anticancer Res 2005; $25: 3641-4$

58. Zellweger T, Benz G, Cathomas G, et al. Multi-target fluorescence in situ hybridization in bladder washings for prediction of recurrent bladder cancer. Int $J$ Cancer 2006; 119:1660-5

59. Hopman AH, Moesker 0, Smeets AW, et al. Numerical chromosome 1, 7, 9, and 11 aberrations in bladder cancer detected by in situ hybridization. Cancer Res 1991;51: 644-51.

60. Hopman AH, Poddighe PJ, Smeets AW, et al. Detection of numerical chromosome aberrations in bladder cancer by in situ hybridization. Am J Pathol 1989;135:1105-17.

61. Waldman FM, Carroll PR, Kerschmann R, et al. Centromeric copy number of chromosome 7 is strongly correlated with tumor grade and labeling index in human bladder cancer. Cancer Res 1991;51:3807-13.

62. Daniely M, Rona R, Kaplan T, et al. Combined analysis of morphology and fluorescence in situ hybridization significantly increases accuracy of bladder cancer detection in voided urine samples. Urology 2005;66:1354-9.

63. Junker K, Fritsch T, Hartmann A, et al. Multicolor fluorescence in situ hybridization (M-FISH) on cells from urine for the detection of bladder cancer. Cytogenet Genome Res 2006;114:279-83.

64. Kipp BR, Karnes RJ, Brankley SM, et al. Monitoring intravesical therapy for superficial bladder cancer using fluorescence in situ hybridization. J Urol 2005;173:401-4.

65. Bubendorf L, Grilli B, Sauter G, et al. Multiprobe FISH for enhanced detection of bladder cancer in voided urine specimens and bladder washings. Am J Clin Pathol 2001;116:79-86

66. Pode D, Shapiro A, Wald $M$, et al. Noninvasive detection of bladder cancer with the BTA stat test. J Urol 1999;161:443-6.

67. Friedrich MG, Hellstern A, Toma MI, et al. Are false-positive urine markers for the detection of bladder carcinoma really wrong or do they predict tumor recurrence? Eur Urol 2003;43:146-50; discussion 150-1. 
68. Diamandis EP. How are we going to discover new cancer biomarkers? A proteomic approach for bladder cancer. Clin Chem 2004;50:793-5.

69. Friedman KM, Fox BA. The promising future of proteomics in cancer diagnosis and treatment. Eur J Gastroenterol Hepatol 2005; 17:701-3.

70. Celis JE, Ostergaard M, Basse B, et al. Loss of adipocyte-type fatty acid binding protein and other protein biomarkers is associated with progression of human bladder transitional cell carcinomas. Cancer Res 1996;56:4782-90.

71. Ostergaard M, Rasmussen HH, Nielsen HV, et al. Proteome profiling of bladder squamous cell carcinomas: identification of markers that define their degree of differentiation. Cancer Res 1997:57:4111-7.

72. Celis JE, Celis $\mathrm{P}$, Ostergaard $\mathrm{M}$, et al. Proteomics and immunohistochemistry define some of the steps involved in the squamous differentiation of the bladder transitional epithelium: a novel strategy for identifying metaplastic lesions. Cancer Res 1999:59: $3003-9$.
73. Chapman K. The ProteinChip Biomarker System from Ciphergen Biosystems: a novel proteomics platform for rapid biomarker discovery and validation. Biochem Soc Trans 2002;30:82-7.

74. Vlahou A, Fountoulakis M. Proteomic approaches in the search for disease biomarkers. J Chromatogr B Analyt Technol Biomed Life Sci 2005;814:11-9.

75. Vlahou A, Schellhammer PF, Mendrinos S, et al. Development of a novel proteomic approach for the detection of transitional cell carcinoma of the bladder in urine. Am J Pathol 2001;158:1491-502.

Correspondence: Dr. Wassim Kassouf, Montréal General Hospital, McGill University Health Centre, 1650 Cedar Ave., Rm. L8-315, Montréal QC H3G 1A4; wassim.kassouf@muhc.mcgill.ca
We accept events for the Calendar section. You may send them to us in the following ways:

\section{Email journal@cua.org}

Fax

514 875-0205
Mail
CUÄ
1155 University Ave.,
Suite 1155
Montréal, QC H3B 3A7

2008 Robotic Prostatectomy Expert Panel-Review Course

June 27-28, 2008

Chicago, IL

Contact: Dr. Kevin C. Zorn

Email: kzorn@surgery.bsd.uchicago.edu

Website: http://RLRPcourse.uchicago.edu

\section{Advances in Female Pelvic Medicine and Reconstructive Pelvic Surgery}

July 10-12, 2008

The Sutton Place Hotel, Toronto, ON

Medical course director: Dr. Harold Drutz

Guest faculty: Dr. Roger Dmochowski, Dr. G. Willy Davila and

Dr. Fred M. Howard

For more information please contact:

Elizabeth Gan

CME - Department of Obstetrics \& Gynaecology

Mount Sinai Hospital / University of Toronto

600 University Ave., Rm. 1255

Toronto ON M5G 1 X5

Phone: 416 586-4800 x2489

Fax: 416 586-5958

Email: egan@mtsinai.on.ca 